\title{
Comparação das variáveis cinemáticas lineares e temporais entre as marchas batida e picada da raça Mangalarga Marchador
}

Mayara Gonçalves Fonseca ${ }^{[a]}$, Jessica Lage lage ${ }^{[a]}$, Consuelo Marelli[b] Thayne de Oliveira Silva ${ }^{[c]}$, Izabella Moreira Marques ${ }^{[d]}$, Gustavo González Monteiro de Barros ${ }^{[e]}$, Cassio Cesar de Matos Sales ${ }^{[0]}$, Amanda Piaia Silvatti ${ }^{[f]}$, Guilherme Camargo Ferraz ${ }^{[a]}$

\footnotetext{
${ }^{[a]}$ Faculdade de Ciências Agrárias e Veterinárias, Universidade Estadual Paulista (UNESP), Jaboticabal, SP, Brasil

${ }^{[b]}$ Médica veterinária, Fortaleza, CE, Brasil

[c] Departamento de Veterinária, Universidade Federal de Viçosa (UFV), Viçosa, MG, Brasil

[d] Escola de Veterinária, Universidade Federal de Minas Gerais (UFMG), Belo Horizonte, MG, Brasil

${ }^{[e]}$ Faculdade de Estudos Administrativos de Minas Gerais (FEAD), Belo Horizonte, MG, Brasil

[f] Departamento de Educação Física, Universidade Federal de Viçosa (UFV), Viçosa, MG, Brasil
}

*Autor correspondente

e-mail: mayaragoncalvesf@hotmail.com

\section{Resumo}

A raça Mangalarga Marchador (MM) admite somente dois tipos de andamentos naturais de velocidade intermediária: marcha batida (MB) ou marcha picada (MP). Estudos de avaliação objetiva desses andamentos são essenciais para racionalizar o processo de seleção e julgamento dos animais. Objetivou-se comparar variáveis cinemáticas lineares e temporais das marchas batida e picada da raça MM. Avaliaram-se 29 equinos de MB e 16 de MP, com faixa etária entre 41 a 111 meses de idade, inscritos na 34a Exposição Nacional do Cavalo MM. Dezoito câmeras PRIME 17w (240 Hz) do sistema Optitrack ${ }^{\circledR}$ de captura optoeletrônica foram posicionadas num percurso de $16 \mathrm{~m}$ de comprimento e $7 \mathrm{~m}$ de largura. Três marcadores retrorreflexivos esféricos de 1,6 cm de diâmetro foram afixados na porção proximal da parede dorsal, na extremidade cranial da pinça e na extremidade caudal do talão lateral dos cascos. Cada equino foi equitado pelo seu apresentador e passou pelo percurso na marcha média, sendo selecionados quatro ciclos de passada completas. As coordenadas tridimensionais (X, Y e Z) e os quadros dos eventos de apoio e decolagem de cada casco foram obtidos de forma visual utilizando o Motive MTV-BDY. Determinaram-se 1) duração, comprimento, frequência e velocidade de cada passada; 2) dissociação de decolagem e de apoio de cada par diagonal; 3) distribuição do tempo da passada em cada tipo de apoio. A dissociação relativa do par diagonal compreendeu o tempo decorrido entre o apoio sucessivo dos membros pélvico e torácico do lado oposto (dissociação de apoio) e o tempo decorrido entre a decolagem sucessiva desses membros (dissociação de decolagem) 
em relação ao tempo total da passada. Os dados foram avaliados quanto à normalidade (Shapiro-Wilk) e à homocedasticidade (Levene). As distribuições dos tempos em cada tipo de apoio foram comparadas pelo teste $U$ de Mann-Whitney e as demais variáveis analisadas pelo teste t de Student $(\mathrm{P}<0,05)$. Animais de MB foram apresentados em velocidade maior (13,10 e 12,08 km/h; P < 0,05), exibiram maior duração (0,523 e 0,504 s; P < 0,001), maior comprimento (1,90 e 1,79 m; P < 0,001) e menor frequência $(1,92$ e 1,98 passadas/s; $\mathrm{P}<0,001$ ) de passadas do que os animais de MP, respectivamente. Isto sugeriu que animais de MP precisariam executar número ainda maior de passadas do que o encontrado nesse estudo para percorrer uma mesma distância se fossem apresentados na mesma velocidade que animais de MB. Em ambas as marchas, a média de dissociação foi negativa, ou seja, na maioria dos animais o casco torácico saiu e chegou ao solo previamente ao casco pélvico. Na MP, houve maior dissociação de decolagem (-30,02 e -4,52\%; P< $0,001)$ e de apoio $(-23,40$ e $-0,18 \% ; P<0,001)$ do que na $M B$, respectivamente. A diferença de dissociação entre os andamentos implicou em distintas distribuições do tempo em cada tipo de apoio. Na MB, a maior porcentagem do tempo da passada foi de apoios bipedal diagonal, seguida de monopedal posterior, tríplice de anterior, bipedal lateral e bipedal de posterior, com baixa frequência de apoios quadrupedais, tríplice de posterior, monopedal de anterior e suspensão. Já na MP, a maior porcentagem foi de apoios laterais seguida por diagonais, tríplice de anterior, monopedal de posterior e houve baixa ocorrência de tríplice de posterior e monopedal de anterior. Sendo assim, a porcentagem em cada tipo de apoio diferiu $(\mathrm{P}<0,05)$ entre $\mathrm{MB}$ e $\mathrm{MP}$, exceto para a porcentagem de apoios monopedais de anteriores $(\mathrm{P}=0,19)$. Do ponto de vista cinemático, as diferenças mais relevantes entre os dois andamentos foram a maior ocorrência de apoios laterais, de tríplices de anterior e de monopedal de posterior, e menor frequência de apoios diagonais na MP em relação à MB. Conclui-se que os andamentos MB e MP foram distintos em todas as variáveis cinemáticas lineares e temporais avaliadas, exceto na porcentagem de apoio de monopedal de anterior.

Palavras-chave: Andamento. Biomecânica. Equino.

Agradecimentos: à Associação Brasileira dos Criadores do Cavalo Mangalarga Marchador; Processo FAPESP no 2015/17.155-2. 